\title{
CAPABILITY-BUILDING COMPETITION IN DESIGN: CASE STUDY
}

\author{
Peter Berg' ${ }^{1}$ Dean Reed ${ }^{2}$, and Shashikala Sriram ${ }^{3}$
}

\begin{abstract}
This paper uses the action research method retrospectively to better understand the development of capability on a series of 7 Higher Education building projects during the architectural planning phase prior to the start of design. The research question is whether Takahiro Fujimoto's explanation of the way Toyota continuously built its capability to deliver automobiles buyers wanted can inform the development of more competitive capability within design and construction companies and together on projects. This paper follows one by the first 2 authors published in the IGLC27 2019 Proceedings in which they use Fujimoto to explain the development of a capability to pre-fabricate and install exterior wall (X-wall) panels for 6 projects during construction. In this new paper the authors share their understanding of Fujimoto's explanation and survey literature they found helpful for understanding what they observed relative to his theory. Then the authors describe "Programmatic Spatial Cost Modeling" and analyze the development, use and competitiveness of this capability across the 7 projects. In closing, the authors share their conclusions in the form of questions and speculations for further research.
\end{abstract}

\section{KEYWORDS}

Theory, kaizen, target cost, capability, information

\section{INTRODUCTION}

The problem inspiring this, and our previous research is the authors' observations of capabilities being developed ad hoc within projects, and then lost because the work routines that comprise these capabilities are not shared or adopted across projects and within design and construction companies. Behind this frustration is the question of how organizations can progressively increase the value they deliver to their customers; the challenge of continuous improvement.

The pieces of this puzzle began to fall into place with Niklas Modig and Par Ahlstrom's explanation of flow efficiency as a Lean operations strategy in This Is Lean (Modig and Ahlstrom 2012). Their praise for The Evolution of a Manufacturing System at Toyota (Fujimoto 1999), encouraged the authors to read The Birth of Lean, which Takahiro Fujimoto edited along with Koichi Shimokaw (2009). The interviews with Taiichi Ohno, Eiji Toyoda, and other figures who shaped Toyota management revealed

Project Executive, DPR Construction, 222 N. 44 ${ }^{\text {th }}$ Street, Phoenix, AZ 85034, USA, peterb@dpr.com, orcid.org/0000-0002-8227-2012

2 Lean/Integration Advocate, DPR Construction, 1450 Veterans Boulevard, Redwood City, CA 94063, USA, deanr@dpr.com, orcid.org/0000-0002-2916-8558

3 Preconstruction Manager, DPR Construction, 222 N. 44 ${ }^{\text {th }}$ Street, Phoenix, AZ 85034, USA, shashis@dpr.com, orcid.org/0000-0001-9314-3163 
how the Toyota Production System evolved mainly through entrepreneurial vision and persistent problem solving.

Next came the challenge of understanding the explanations Fujimoto provides in The Evolution of a Manufacturing System at Toyota. The challenge is that he doesn't provide examples of Toyota's routines for manufacturing and learning, including problem-solving. The same is true for the processes for evolutionary learning. This made it difficult to devise a plan for validating available cases against his theory of capability-building to answer the authors' question about building capability within and across projects and organizations.

Fortunately, those gaps have been filled by others with deep knowledge of these subjects. In 2008 John Shook published Managing to Learn in which he described how people can use the A3 tool he was taught as a Toyota employee to learn and implement their plans for improvement (Shook 2008). In 2010 Mike Rother published Toyota Kata to explain why and how Toyota coaches its employees and partners as they solve problems so they can continually improve performance (Rother 2010). Charles Duhigg explained how habits form from routines in his book Habit (2012). Art Smalley, who learned problem-solving as a Toyota employee, explained the mindset, skills and actions required to solve the four types of problems people encounter as they work to deliver products and services in his 2018 book, Four Types of Problems (Smalley 2018).

Unlike the IGLC 2019 paper (Berg and Reed 2019), which focused on developing capability on 6 different projects to prefabricate exterior wall panels on the construction sites and install them, this one seeks to address the question of whether Takahiro Fujimoto's theory of Toyota-style capability-building can be applied to the planning and design of buildings. In this study, the method is applied to capability-building for "Programmatic Spatial Cost Modeling" prior to design development on a series of 7 building projects. As with last year's study, the authors use Fujimoto's theory to analyze and explain the development and competitiveness of this new capability across all the projects where it has been applied.

\section{THE BREAKTHROUGH FOR PROGRAMMATIC SPATIAL COST MODELING}

In response to an earnest request from the campus architect for a major university, and inspired by the accomplishments of Haahtela Oy (Pennanen and Ballard 2008) (Pennanen et al. 2010), , the General Contractor's preconstruction team developed a program and concept design validation process in collabortion with the Project Architect's team. The campus architect already had 6 large projects far into design that were all far over budget and late resulting in major cost impacts, late starts and general disappointment with the delivery process. He challenged the GC and Architect to develop a way to prove the program and concept design were within budget before he would approve proceeding with schematic design.

Through a series of workshops, the GC team collaborated with the architectural team to streamline the design, preconstruction and BIM processes. A high-level understanding of the program and a visioning session were all that the GC and Architect needed to formulate a comparable analysis, based upon similar projects pulled from the GC's historical cost database, to predict that the project was $20 \%$ over budget.

While programming interviews were being conducted the architectural team began shaping the concept design. The GC requested that they include 3-D isometric room models, dimensioned floor plans and room data sheets in the program manual along with 
narratives provided by the Mechanical, Electrical and Plumbing consultants. Utilizing the program manual, the GC team produced construction document level cost data for each room including MEP cost prorations that resulted in a clearly delineated program cost separate from the core, shell and site. The initial concept design was then priced to complete the estimate, which again concluded that the project was $20 \%$ over budget.

The owner recognized that their original project vision exceeded available funding and directed the GC and Architect to provide an alternative menu of options that would bring the program and concept design within budget. Closely aligned, the teams immediately began providing high, medium and low-cost options for all major building components, materials and systems. The architectural team utilized script-based algorithms to rapidly develop and test a large variety of blocking and stacking configurations within their BIM design software. Using the already generated room costs, the GC was able to rapidly price each configuration in a matter of keystrokes.

Initially there was concern that constraining the architecture with cost so early in the process would limit creativity. However, it had the opposite effect, inspiring designers to imagine a myriad of solutions that otherwise would not have been considered, one of which became the chosen design solution. The architectural team began creating sets of concept designs that the GC accurately priced within 24-hours, made possible by the GC's deep integration of BIM with model-based costing. The GC team priced 55 concept designs within a one-month timeframe. This unique process allowed the team to present an array of combined options within budget that the owner could choose from based upon what they valued most. Each combination presented trade-offs to arrive within budget; for example, a higher cost exterior envelope material palette combined with medium interior finishes and a less efficient mechanical system.

Ultimately the owner chose a less expensive exterior material palette, medium-range interiors and a higher efficiency mechanical system to bring the project within budget. The university was very pleased with the final design and having proven the program and concept design were within budget, the campus architect directed the team to proceed with schematic design. The design team utilized the GC's granularly transparent roombased costing, detailed quantities, levels of finish, product types, etc. as a road map for designing to budget. Continuing with an integrated approach, GC and architectural team progressed the design through schematic and design development trending within .5\% of the project budget, landing the project within budget at construction document completion.

This process dramatically minimized the painful traditional value-engineering redesign cycle the campus architect sought to avoid. The university reported this was the best project delivery by a large margin they had ever experienced and are demanding their other teams adopt a similar approach. The GC has been awarded subsequent projects for the university as a direct result of this performance.

The GC team thought this approach would be difficult to implement with other architects and owners. However, they have now implemented it on 3 subsequent projects with different owners and architects. The process has been well received by the architects and eagerly adopted by one in particular that has requested that the GC operate directly in their model to inform cost during programming and concept design. Architects really appreciate the early granular transparency and how the GC packages costs according to the way they design, which allows them to be more efficient by designing to budget while not pursuing unrealistic ideas. Owners appreciate the predictability, transparency and opportunity to evaluate and select what they believe provides the greatest value from a wide variety of options. 


\section{THEORY OF CAPABILITY-BUILDING COMPETITION}

\section{Prior Characterizations}

Flávio Picchi highlights Fujimoto's theory of Toyota's evolutionary capability-building in an IGLC paper published in 2001, just 2-years after the Evolution book, titled "System View of Lean Construction Application Opportunities" (Picchi 2001). He describes it as an evolutionary perspective focusing on "three levels of capability that explain the Toyota Production System's sustained high performance and continuous improvement:"

- Standard and effective routines for performing activities in all company processes (Routinized manufacturing capability);

- Routines for problem identification and solving and solution retention (Routinized learning capability);

- Intentional and opportunistic learning capability of handling system changes in developing the manufacturing and learning routine capabilities (Evolutionary learning capability)

Picchi notes that Fujimoto sees manufacturing activities as an information system and summarizes the production capability of Toyota and other effective Japanese automakers as "dense and accurate information transmission between flexible (information-redundant) productive resources (Fujimoto 1999 p. 108)." Density is the transmission of accurate information at a regular pace to increase productivity, efficiency, and the elimination waste. Accuracy of information transmission determines quality for Toyota according to Fujimoto.

Niklas Modig interfaced with Fujimoto while in Japan between April 2006 and March 2008 during Modig's study of the Toyota car dealer network as a participant in a larger research program at the Manufacturing Management Research Center at the University of Tokyo. In Chapter 6 of the book, This Is Lean, devoted to summarizing important works explaining Toyota, Niklas Modig and Par Ahlstrom cite Fujimoto's Evolution book and make the following points:

- Toyota developed the three different levels of capabilities noted by Picchi;

- The key to Toyota's success is the capability of always ensuring development, regardless of what setbacks or obstacles the company encounters

- Toyota-style manufacturers create flow by focusing on value-receiving time created through dense information transmission rather than speed of individual activities.

Neither Modig and Ahlstrom, or Picchi describe "multi-path system emergence," the way routines develop and are extended to improve or replace processes within Toyota. This paper's authors include it because of the relevance the development of routines has for understanding evolutionary learning and system emergence.

\section{AUTHORS' UNDERSTANDING}

The authors' understanding of Fujimoto's theory of Toyota-style capability-building, which is the basis of analysis, is as follows.

- Routines: tools, activities and behaviors are encompassed in routines to carry out formal or informal processes to produce part of a product or service. 
- Multi-path development: routines come from multiple sources, which are not mutually exclusive:

- Rational calculation: planning a change in work processes

- Environmental constraints: routines created in response to one or more external constraints

- Entrepreneurial vision: a manager / leader persuades team member to work differently

- Knowledge transfer: a team is exposed to a better way of working, learns and adopts it

- Random trials: a team decides to try different approaches and adopt the best one without knowing which will be best beforehand

- Problem-solving is central to learning routines for improving manufacturing routines. This work contributes information that can be used to improve both the product and process performance, which can lead to increased capability and better and higher quality products and services.

- The two types of routines considered here are those for production and for learning.

- Manufacturing is the imprinting of information on media. Products should be seen as bundles of information useful to the customer. This includes automobiles, and by extension the built environment in the eyes of the authors.

- Toyota-style flow efficiency is based on density of information transmission rather than speed of individual operations. Density is the regular and timely transmission of accurate information to receivers for transfer to media exactly when required for delivery to the next customer based on the final customer's order.

- Eliminating or reducing the Seven Wastes identified by Taiichi Ohno serves to increase density by eliminating time where receivers cannot consume or act on information.

- The adoption of new routines may or may not result in a better capability than competitors possess.

- Evolutionary learning is the capability for capability-building. This can be accidental or intentional, episodic or planned when those with authority stop to consider how heretofore separate capabilities can be integrated. This is how the Toyota Production System emerged and is available to other organizations which understand capability-building well enough to undertake system development.

\section{CASE STUDY ANALYSIS}

\section{ASSESSMENT FraMEWORK}

The authors used the framework they developed for a previous study based on Fujimoto's theory (Berg and Reed 2019) to asses the competitiveness of routines, and extent of multipath system emergence a nd evolutionary learning capability for 7 projects

\section{Competitiveness Above Current Standard Practice}

- Assessment: the first author of this paper acted as entrepreneur, process designer and coach / mentor while serving as the GC Project Executive for the $1^{\text {st }}, 2^{\text {nd }}, 3^{\text {rd }}$, 
and $4^{\text {th }}$ projects listed in Tables 1 and 2 below, and was entirely accountable for project team performance on these projects. He also assisted the teams for the $5^{\text {th }}$, $6^{\text {th }}$, and $7^{\text {th }}$ projects. His role seems at least partially analogous to the Chief Engineer in Toyota's product development system (Sobek et al. 1998). The third author modeled program cost on all 7 projects. Together, they were well qualified to assess competitiveness, evolutionary learning and multi-path emergence in the absence of well-defined quantifiable criteria.

- Success criteria: six were defined by project stakeholders: (1) eliminate redesign; (2) model the cost of program space; (3) budget drives decision-making; (4) costing detailed options prior to selection; (5) schedule savings; and (6) accuracy: Guaranteed Maximum Price (GMP) $<=1 \%$ of $1^{\text {st }}$ base estimate. The authors of this paper realized during an initial scoring exercise that use and effectiveness of each routine applied equally to all of the success criteria because of their interdependence.

- Routines: nineteen routines, listed in Table 1 , were identified by the $3^{\text {rd }}$ author for the projects, all of which require skill in working with data tools, and partners collaboratively. The routines built on proceeding routines. This interdependency made it problematic to assign greater or lesser importance to them individually. In this analysis, all of the routines were considered to have the potential to contribute equally to each success criteria, not exceeding 100\% improvement.

- Competitiveness: The contribution for each routine was calculated based on its score using a 0 to 10 scale, with the maximum limited to $5.26 \%$ for each routine as one of 19. The improvement in competitiveness score was the total for all 19 of each project's routines.

\section{Multi-path System Emergence, Firm Specific Patterns of Routine Capabilities \& Evolutionary Learning Capability}

- Multi-Path System Emergence: a score of 0 or 1 was given for the presence of each of the 5 paths identified by Fujimoto, described above. The sum of these scores divided by a possible of 19 determined the percentage for each path's contribution to generating solutions for each of the 7 projects.

- Firm Specific Patterns of Routine Capabilities: a score of 0 to 5 was given for the degree to which the 19 routines had been implemented ("routinization"). The sum of these scores divided by a possible total of $95(5 * 19)$ determined the total score for each project.

- Evolutionary Learning Capability: a score of 0 or 1 was given to for each routine that was a product of evolutionary learning. The sum of these scores divided by a possible of 19 determined the total score for each project.

\section{Assessment of Programmatic Spatial Cost Modeling Capability}

Table 1 shows the first author's assessment of the routines' contribution to success, defined as eliminating design rework, modeling program cost, making budget-driven decisions, providing cost for detailed options, schedule savings and cost accuracy, compared to the standard practice of estimating the cost of design.

Table 2 shows the first author's assessment of Multi-Path Development, Firm Specific Patterns of Routine Capabilities and Evolutionary Learning Capability, and their contribution to Programmatic Spatial Cost Modeling capability. 
Table 1: Capability Routines Contribution to Competitiveness

\begin{tabular}{|c|c|c|c|c|c|c|c|c|}
\hline ID & $\begin{array}{c}\text { Routines Contribution \% } \\
\text { by Project }\end{array}$ & 1 & 2 & 3 & 4 & 5 & 6 & 7 \\
\hline 1 & Stakeholder commitment & 0 & 0 & 1.6 & 3.7 & 2.6 & 0 & 2.6 \\
\hline 2 & Work methods alignment & 0 & 0 & 0 & 4.2 & 0 & 0 & 2.6 \\
\hline 3 & Data-mining space cost & 0 & 0 & 0 & 4.2 & 3.2 & 3.7 & 1.6 \\
\hline 4 & Room finishes info & 0 & 0 & 0 & 4.2 & 3.7 & 2.6 & 4.2 \\
\hline 5 & Programmatic spatial BIM & 0 & 0 & 0 & 4.2 & 2.6 & 0 & 1.6 \\
\hline 6 & Costs and categories alignment & 0 & 0 & 0 & 4.2 & 2.6 & 0 & 2.6 \\
\hline 7 & $\begin{array}{l}\text { Owner program benchmark cost } \\
\text { model }\end{array}$ & 1.1 & 0 & 1.1 & 4.2 & 3.7 & 3.7 & 1.6 \\
\hline 8 & Program draft cost model & 0 & 0 & 0 & 4.2 & 3.2 & 3.7 & 1.6 \\
\hline 9 & Massing options cost model & 0 & 2.1 & 0 & 4.7 & 2.6 & 2.6 & 2.6 \\
\hline 10 & Detailed line-item cost models & 0 & 0 & 0 & 4.7 & 3.2 & 3.7 & 2.6 \\
\hline 11 & Cost model simulations & 0 & 2.1 & 0 & 4.7 & 2.6 & 2.6 & 3.7 \\
\hline 12 & Finalize building program & 0 & 0 & 0 & 4.2 & 3.2 & 3.7 & 3.7 \\
\hline 13 & Establish target value buckets & 1.1 & 0 & 1.1 & 4.7 & 3.2 & 4.2 & 3.2 \\
\hline 14 & Target value tracking & 1.6 & 0 & 1.1 & 4.7 & 3.2 & 4.2 & $5.3 \%$ \\
\hline 15 & Schematic design estimate & 1.6 & 2.1 & 1.6 & 4.7 & 2.6 & 3.2 & $4.7 \%$ \\
\hline 16 & Continue target value tracking & 1.6 & 1.6 & 1.6 & 4.7 & 2.6 & 4.2 & $5.3 \%$ \\
\hline 17 & $\begin{array}{c}\text { Design Development / GMP } \\
\text { estimate }\end{array}$ & 1.6 & 2.1 & 1.6 & 4.7 & 2.6 & 3.7 & $4.7 \%$ \\
\hline 18 & Program cost data for re-use & 0 & 0 & 0 & 4.7 & 3.7 & 4.2 & $5.3 \%$ \\
\hline 19 & Construction Documents estimate & 1.6 & 1.6 & 1.6 & 4.7 & 2.6 & 4.7 & $4.7 \%$ \\
\hline \multicolumn{2}{|r|}{ Improvement in Competitiveness \% } & 10 & 12 & 11 & 85 & 54 & 55 & 64 \\
\hline
\end{tabular}


Table 2: Multi-path System Emergence \& Evolutionary Learning Capability4

\begin{tabular}{cccccccc}
\hline Project & RC & EC & EV & KT & RT & PRC & ELC \\
\hline 1 & $37 \%$ & $0 \%$ & $0 \%$ & $32 \%$ & $0 \%$ & $13 \%$ & $0 \%$ \\
2 & $32 \%$ & $0 \%$ & $16 \%$ & $21 \%$ & $0 \%$ & $14 \%$ & $16 \%$ \\
3 & $42 \%$ & $0 \%$ & $0 \%$ & $37 \%$ & $0 \%$ & $23 \%$ & $0 \%$ \\
4 & $100 \%$ & $0 \%$ & $68 \%$ & $37 \%$ & $0 \%$ & $37 \%$ & $74 \%$ \\
5 & $95 \%$ & $0 \%$ & $5 \%$ & $95 \%$ & $0 \%$ & $40 \%$ & $5 \%$ \\
6 & $89 \%$ & $0 \%$ & $0 \%$ & $89 \%$ & $0 \%$ & $51 \%$ & $0 \%$ \\
7 & $95 \%$ & $5 \%$ & $16 \%$ & $95 \%$ & $0 \%$ & $69 \%$ & $5 \%$ \\
\hline
\end{tabular}

\section{FINDINGS}

\section{Competitiveness}

- Team members were not able to follow several of the initial routines in the first 3 projects requiring historical cost data for program space, which the GC did not have until the $4^{\text {th }}$ project, after developing the capability to extrapolate spatial from system-based cost data accurately.

- The data indicates sequential dependency between routines. What the numbers don't show was that in real-life they often overlapped, that they were reciprocally interdependent. Information was being passed back and forth between architectural and building team members for more than a single routine at a given time. A case in point is the use of use of BIM by the architectural team as a repository for the size, characteristics and contents of spaces. Having these quantities enabled the GC's estimators to provide rapid feedback on cost to the architects.

- The $4^{\text {th }}$ project had the highest median and overall competitiveness. While the scores of some routines improved in the $5^{\text {th }}, 6^{\text {th }}$, and $7^{\text {th }}$ projects, and all were significantly better than the first 3 projects, their scores were lower than the $4^{\text {th }}$ project.

\section{Multi-Path System Emergence}

- Levels of rational calculation (RC), entrepreneurial vision (EV) and knowledge transfer (KT) were present, but low in the first 3 projects. While there was a modest increase in $\mathrm{KT}, \mathrm{RC}$ and $\mathrm{EV}$ increased significantly in the $4^{\text {th }}$ project. $\mathrm{RC}$ remained high and KT increased and EV decreased dramatically in the $5^{\text {th }}, 6^{\text {th }}$, and $7^{\text {th }}$ projects.

\footnotetext{
${ }^{4}$ Paths are abbreviated as follows: RC for Rational Calculation; EC for Environmental Constraints; EV for Entrepreneurial Vision; KT for Knowledge Transfer; and RT for Random Trials. PRC stands for Firm Specific Patterns of Routine Capabilities, and ELC for Evolutionary Learning Capability.
} 


\section{Firm Specific Patterns of Routine Capabilities}

- Firm specific patterns of routine capabilities (PRC) increased steadily from the $1^{\text {st }}$ to the $7^{\text {th }}$ project. The curve was more pronounced between the $2^{\text {rd }}$ and $4^{\text {th }}$ projects, and even more so between the $5^{\text {th }}$ and the $7^{\text {th }}$.

\section{Evolutionary Learning Capability}

- Evolutionary learning capability (ELC) was present in the $2^{\text {nd }}$ project and increased dramatically in the $4^{\text {th }}$ project and fell below the level of the $2^{\text {nd }}$ in the $5^{\text {th }}, 6^{\text {th }}$, and $7^{\text {th }}$ projects.

\section{CONCLUSION}

At this early point in researching the application of Takahiro Fujimoto's theory of capability-building competition within the Construction Industry, we only have questions and speculations to guide further research and experiments within projects.

\section{QUESTIONS}

1. What explains the difference in learning and competitiveness trends observed in the research described in last year's study of exterior wall panel construction and this year's look at establishing an achievable target cost prior to the start of design? The numbers for Firm Specific Patterns of Routine Capabilities (PRC) and Evolutionary Learning Capability (ELC), and competitiveness increased progressively from one project to the next for construction of exterior wall panels. That was not the case for Programmatic Spatial Cost Modeling.

2. Although much higher in the $5^{\text {th }}, 6^{\text {th }}$, and $7^{\text {th }}$ projects following the breakthrough in the $4^{\text {th }}$, why did competitiveness decrease rather than continue to increase?

3. How significant was the demand by the customer that the supply chain (the GC and Architect) provide a much higher level of certainty on the $4^{\text {th }}$ project?

4. Are customer pull, entrepreneurial vision and effective problem-solving linked? All of these were in play only on the $4^{\text {th }}$, most competitive project.

5. Are entrepreneurial vision and evolutionary learning capability linked? As noted above, they both scored high only in the $4^{\text {th }}$ project.

6. Related to question 2 , is entrepreneurial vision necessary in combination with knowledge transfer to sustain the kind of breakthrough evident in project 4 ?

7. Are the data and questions they provoke indicators of a difference between capability-building in Manufacturing versus Construction? For example, rational calculation, which the Fujimoto equates to deliberate planning, was high in the projects with significant increases in competitiveness, which may not be the case in maintaining routines in Manufacturing. This may be due to the fact that owners changed as well as the staff for the same owner from project to project. The architects for the $4^{\text {th }}, 5^{\text {th }}, 6^{\text {th }}$, and $7^{\text {th }}$ projects were all different. Although customers are many and different in Manufacturing, product development, engineering, production staff and even suppliers do not change to the extent they do in Construction projects 


\section{SPECULATIONS}

- The fall-off in competitiveness may result from different levels of capability for BIM and collaboration within the architectural teams for the $5^{\text {th }}, 6^{\text {th }}$, and $7^{\text {th }}$ projects.

- The first author is certain that the strong customer demand at the highest level was the single key factor because this made it clear to the owner, GC and architectural team members in the $4^{\text {th }}$ project that they needed to do something different and thereby risk losing time if the new approach didn't work, which the GC team had been unwilling to do on the first 3 projects. What happens if there is no pull from the customer to motivate enough team members within participating organizations to change? In these cases, it would seem that entrepreneurial vision must remain strong, and be shared within the project senior leadership team.

- Problem-solving is considered a technique for returning to normal or improving, and often overlooked as a source of information and increasing capability. Could it be that customer pull and entrepreneurial vision must be present in-person or through institutionalization for problem-solving to create both information and the opportunity for learning that is a prerequisite for capability-building?

- Density of transmission of useful information appears to have been high in the last 4 projects. Could it have mirrored the effective use of BIM and the degree of collaboration between the GC and Architect teams? Information was sent back and forth in small batches specified by the receivers at the times requested. This type of exchange is consistent with reports from project teams that became very well integrated, although density was not in the vocabulary of those teams. One major difference in the cases of projects 4, 5, 6 and 7 was how early this integration happened. Could this be a result of participation in structured routines enabled by BIM?

- The first author served as visionary entrepreneur, system designer, leader, coach and mentor for the first 4 projects, which seems to be essential for evolutionary learning capability. Could it be that these are the essential leadership capabilities required for temporary organizations to develop organizational capabilities? Should project teams identify and empower a Chief Engineer to develop the capabilities required for a dense information transmission strategy?

- As noted above, the first author / entrepreneur shifted from project leader to an advisory role on the $5^{\text {th }}, 6^{\text {th }}$, and $7^{\text {th }}$ projects. The data indicates that knowledge transfer is not sufficient by itself to overcome the loss of entrepreneurial vision in building capability over a series of projects. This is likely because knowledge transfer is typically focused on methods, processes, tools and actions. Perhaps the first entrepreneur or Chief Engineer must mentor at least one team member to assume that role for the next project, and so on? Although Mike Rother does not speak of entrepreneurial vision in his Toyota Kata book, he explains that the katas (individual training exercises) are the mechanism Toyota has historically used to build the capabilities to move in the direction set through Hoshin Kanri (policy deployment) to guide every employee's work (Rother 2010). 


\section{REFERENCES}

Berg, P. and Reed, D. (2019). "Capability-Building Competition in Construction: Case Study Reinterpretation." Proc. $27^{\text {th }}$ Annual Conference of the International Group for Lean Construction, Dublin, Ireland, 265-274.

Duhigg, C. (2012). The power of habit: why we do what we do in life and business. Random House, New York.

Fujimoto, T. (1999). The Evolution of a Manufacturing System at Toyota. Oxford University Press, Inc., New York, New York.

Modig, N. and Åhlström, P. (2012). This is lean: resolving the efficiency paradox. Rheologica Publishing, Stockholm.

Pennanen, A. and Ballard, G. (2008). "Determining Expected Cost in the Target Costing Process." Proc. $16^{\text {th }}$ Annual Conference of the International Group for Lean Construction, P. Tzortzopoulos and M. Kagioglou, eds., Manchester, UK, 589-600.

Pennanen, A., Ballard, G., and Haahtela, Y. (2010). "Designing to Targets in a Target Costing Process." Proc. $18^{\text {th }}$ Annual Conference of the International Group for Lean Construction, K. Walsh and T. Alves, eds., Haifa, Israel, 161-170.

Picchi, F.A. (2001). "System View of Lean Construction Application Opportunities." Proc. $9^{\text {th }}$ Annual Conference of the International Group for Lean Construction, G. Ballard and D. Chua, eds., Singapore, Singapore.

Rother, M. (2010). Toyota Kata: Managing People for Improvement, adaptiveness, and superior results. McGraw Hill, New York.

Shimokawa, K. and Fujimoto, T. (Eds.). (2009). The Birth of Lean: Conversations with Taiichi Ohno, Eiji Toyoda, and other figures who shaped Toyota management. The Lean Enterprise Institute, Cambridge, Massachusetts.

Shook, J. (2008). Managing to learn: using the A3 management process to solve problems, gain agreement, mentor and lead. Lean Enterprise Institute, Cambridge, Massachusetts.

Smalley, A. (2018). Four Types of Problems from reactive troubleshooting to creative innovation. Lean Enterprise Institute Inc., Cambridge, MA, USA.

Sobek, D. K., Liker, J. K., and Ward, A. C. (1998). "Another Look at How Toyota Integrates Product Development." Harvard Business Review, (July-August 1998 Issue), 12 . 
Capability-Building Competition in Design: Case Study

This page is intentionally left blank. 